\title{
The intricacies of the stacking interaction in a pyrrole-pyrrole system
}

\author{
Tomasz Sierański ${ }^{1}[0$
}

Received: 20 November 2015/ Accepted: 17 December 2015/Published online: 5 January 2016

(C) The Author(s) 2015. This article is published with open access at Springerlink.com

\begin{abstract}
Extensive calculations of potential energy surfaces for parallel-displaced configurations of pyrrole-pyrrole systems have been carried out by the use of a dispersion-corrected density functional. System geometries associated with the energy minima have been found. The minimum interaction energy has been calculated as $-5.38 \mathrm{kcal} / \mathrm{mol}$. However, bonding boundaries appeared to be relatively broad, and stacking interactions can be binding even for ring centroid distances larger than $6 \AA$. Though the contribution of the correlation energy to intermolecular interaction in pyrrole dimers appeared to be relatively small (around 1.6 smaller than it is in a benzenebenzene system), this system's minimum interaction energy is lower than those calculated for benzene-benzene, benzene-pyridine and even pyridine-pyridine configurations. The calculation of the charges and energy decomposition analysis revealed that the specific charge distribution in a pyrrole molecule and its relatively high polarization are the significant source of the intermolecular interaction in pyrrole dimer systems.
\end{abstract}

Keywords Stacking interactions $\cdot$ Pyrrole $\cdot$ Ab initio calculations · Intermolecular interactions · Density functional theory

Tomasz Sierański

tomasz.sieranski@p.lodz.pl

1 Institute of General and Ecological Chemistry, Lodz University of Technology, Zeromskiego 116, 90-924 Lodz, Poland

\section{Introduction}

Non-covalent interactions (NCI) are inarguably of a great importance in chemical, catalytic and especially in biological systems. They play a key role in supramolecular chemistry which is defined as "chemistry beyond the molecule" and are without doubt the dominant type of interaction in maintaining the three-dimensional structure of large systems such as proteins, nucleic acids and other large molecules [1-8]. In these systems, NCI involving aromatic rings can be distinguished and those are for instance: $\pi$-stacking, cation $/ \pi$, anion $-\pi, \mathrm{C}-\mathrm{H} / \pi$ and $\mathrm{N}-\mathrm{H} / \pi$ interactions [9-14]. The understanding of their nature together with their interplaying and dependencies between different types of NCI (for instance $\pi$-stacking vs $\mathrm{N}-\mathrm{H} / \pi$ ) is critical for harnessing their full potential in chemistry, especially when the precise control of the strength and geometry of intermolecular interactions is concerned, e.g. in the material improving processes and drug design strategy. The quantification of the intermolecular interactions in the aromatic ring systems is also extremely significant in understanding the structures of molecular assemblies [15, 16].

Among NCI involving aromatic ring systems, the ones containing heteroaromatic rings have recently received greater attention [17-22]. Such rings are building blocks for anchoring substituents in defined positions and are a crucial component in most known drug molecules. It is not surprising that because of their distinctive electronic properties they are involved in various interaction patterns including for instance $\pi$-stacking and hydrogen bonds. However, compared with benzene-benzene ring systems in case of which a wide range of computational and experimental methods have been applied [23-27], the studies of the intermolecular interactions of aromatic heterocyclic 
ring systems are far less numerous. It is particularly observed for five-membered rings. Though some attention has been paid to thiophene $[17,28,29]$ and, especially recently, to several other compounds (e.g. furan and oxazole) [17], this topic is still poorly explored. This may seem to be unexpected since many heteroatomic ring-based compounds, especially containing an N-heterocyclic ring, are ubiquitous in a large number of biochemical processes. Additionally, the study of NCI in these systems may disclose new aspects related to the origin of such interactions (e.g. associated with the interplay of two significant factors: electrostatic effects and London dispersion). N-heterocyclic aromatic rings have more $\pi$-electrons in their ring frameworks than only carbon-based ones (e.g. benzene). When five-membered aromatic $\mathrm{N}$-heterocycles are considered, their ring frameworks are even richer in $\pi$-electrons since the $\pi$-electrons are distributed over lesser number of ring atoms (e.g. pyridine vs pyrrole). Taking all the above into account, as the main focus of this study, the extensive analysis (the interaction energies of approximately 8000 systems have been calculated) of potential energy surfaces (PES) of model pyrrole-pyrrole dimers was chosen. The pyrrole molecule as the study object was selected due to its specific electronic properties and the presence of a pyrrole ring in a variety of biological systems $[30,31]$. A pyrrole molecule (unlike pyridine one) possesses its nitrogen atom connected to a hydrogen atom and relative to benzene with six $\pi$-electrons in its carbon framework, it possesses six $\pi$-electrons distributed over five atoms. Hence, as a heteroatomic planar and electronrich ring, it is a useful recognition element in many biological contexts in which it may be engaged in creation of different sorts of NCI such as hydrogen bonds and $\pi$ stacking [32, 33]. Pyrrole-containing molecules include commonly naturally produced compounds such as chlorophyll, chlorins, vitamin B12 and porphyrinogens [34-36]. A pyrrole ring is also a part of tryptamines including serotonin, melatonin and many other biologically important substances [37-40]. For that reason, apart from broadening our knowledge of the stacking interaction phenomenon itself, this extensive study of the intermolecular interaction in model pyrrole systems may be relevant in electronic properties of pyrrole-unit-based drugs. Furthermore, due to pyrrole's electronic properties enabling stacking interactions and formation of $\pi$-ligands for metal coordination [41, 42], pyrrole molecules may be useful building blocks for nanoscale supramolecular structures [43]. To summarize, the present study will definitely shed more light on stacking interactions (especially enabling to understand the nature of the forces governing their strength) and may help to understand acceptor and donor abilities of five-membered heterocycles. It might also appear to be significant in revealing the structure-stability relationships that govern supramolecular system formation, opening the door to the rational design of pyrrole-based ligands.

The study of NCI is a challenging task for both computational and experimental approaches [44]. In case of aromatic ring systems, the NCI have been extensively studied by means of crystal structure analysis and spectroscopic measurements [15]. Although these studies provide a variety of useful information, compared with computational methods, the experimental techniques suffer from lack of direct information about a particular interaction [45]. The most difficult task calculating the $\mathrm{NCI}$ interaction energies is associated with the appropriate description of dispersion forces. A method that in most cases accurately predicts the energy of such type of interactions is coupled cluster with single, double and perturbative triple excitation contributions known as $\operatorname{CCSD}(\mathrm{T})[45,46]$. This method, however, currently cannot be used routinely due to its large computational cost making the calculation feasible only for small, single molecular systems. More advanced methods such as CCSDTQ (coupled cluster with single, double, triple and quadruple excitations) are used very rarely and are applicable only for very small systems such as a water dimer [47]. An alternative to those wave function theory (WFT) methods are density functional theory (DFT) methods whose cost, compared with WFT methods in general, is relatively low. Moreover, over the recent 10 years, there has been an enormous improvement in DFT approaches to the energy calculation of non-covalently bonded systems [48, 49]. The use of DFT techniques with dispersion corrections often appeared to surpass MP2 (second-order Møller-Plesset perturbation theory [50]) with the use of a triple-zeta correlation-consistent basis set. Newly developed DFT methods such as B97-D3 (with D3 version of Grimme's dispersion with Becke-Johnson damping) [51] have performed even better giving in many cases the energy values close to those obtained from $\operatorname{CCSD}(\mathrm{T})$ [52].

Taking into account many systems of which the interaction energies were to be calculated, the DFT method has been selected. In order to select a suitable DFT functional for the performed study, a reference method was needed. Although a reference energy surface was created on the basis of the interaction energies of 49 systems, $\operatorname{CCSD}(\mathrm{T})$ calculations with the use of complete basis set (CBS) extrapolation were employed.

\section{Experimental}

Pyrrole-pyrrole model systems were constructed as shown in the Fig. 1. In each of them, the pyrrole rings were parallel to each other. PES scans were done as a function of 


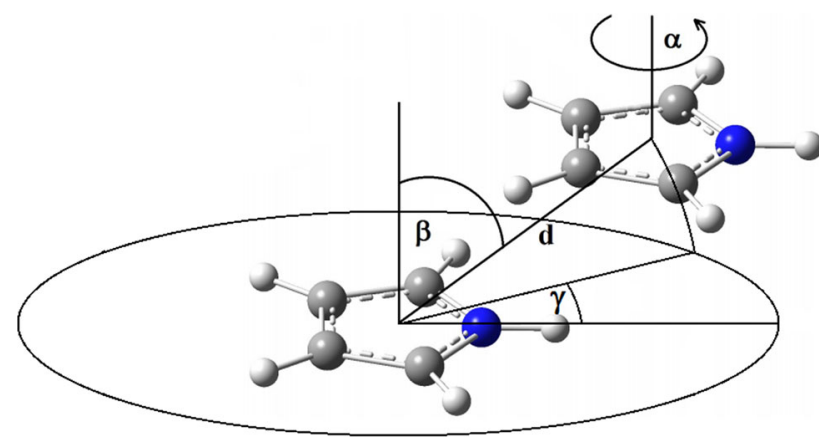

Fig. 1 Geometrical model of a pyrrole dimer used in presented calculations ( $d$ - the aromatic ring centre distance; $\alpha$-the twist angle between the monomers; $\beta$ - the angle between the line connecting the aromatic ring centres and the normal line to the aromatic ring in which the connecting centre line starts; $\gamma$-the angle determining the rotation of one monomer around the other)

four geometrical parameters: the aromatic ring centre distance $(d)$, the twist angle $(\alpha)$ between the monomers, the angle between the line connecting the aromatic ring centres and the normal line to the aromatic ring in which the connecting centre line starts $(\beta)$ and the angle determining the rotation of one monomer around the other $(\gamma)$. All calculations were performed using Gaussian 09, Revision D.01 [53]. The starting monomer was a pyrrole molecule with geometry optimised at MP2/aug-cc-pVDZ level. The dimer energies were corrected for basis set superposition error by the use of the counterpoise method [54]. Interaction energies were calculated by subtracting the energy of the two monomers:

$E_{\text {Interaction }}=E_{\text {Dimer }}-E_{\text {Monomer A }}-E_{\text {Monomer B }}$

In order to identify an appropriate DFT functional for the PES study, the PES scan of the selected pyrrole-pyrrole model systems (Fig. 2) was performed at the CCSD(T)/ CBS level of theory using aug-cc-pVDZ and aug-cc-pVTZ basis sets [55] to obtain the MP2/CBS limit energy through the extrapolation scheme as described by Helgaker et al. [56]:

$E^{\mathrm{CBS}}=\frac{X^{3} E_{(X)}-Y^{3} E_{(Y)}}{X^{3}-Y^{3}}$

where $X=2$ and $Y=3$, for the aug-cc-pVDZ $\rightarrow$ aug-cc$\mathrm{pVTZ}$ extrapolation that was used in this work. $E_{(X)}$ and $E_{(Y)}$ are the MP2 energy values calculated with the use of aug-cc-pVDZ and aug-cc-pVTZ basis sets, respectively, for $E_{(X)}$ and $E_{(Y)}$. As it was shown earlier, the difference between CCSD(T) and MP2 energy has negligible (until a too small basis set is used) basis set dependence [57]. Hence, in order to obtain CCSD(T)/CBS energy, the difference between CCSD(T)/aug-cc-pVDZ and MP2/aug-ccpVDZ was added to the extrapolated MP2/CBS energy. The pyrrole-pyrrole system energies were calculated as a

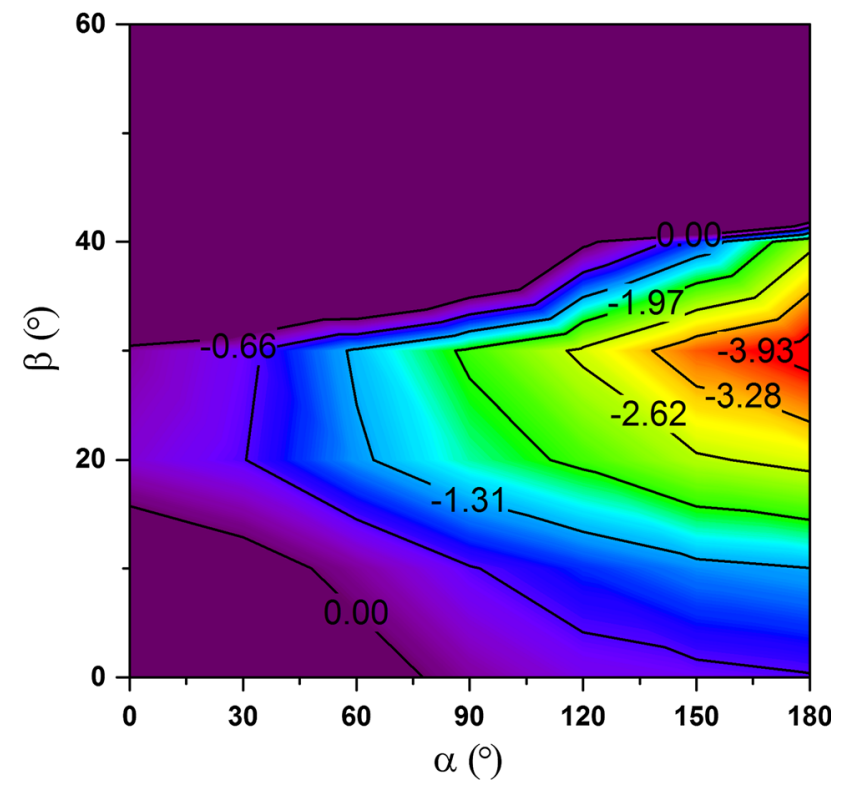

Fig. 2 Reference PES map for the selected pyrrole-pyrrole model systems $\left(d=3.5 \AA, \gamma=0^{\circ}\right)$. The presented interaction energy values are given in $\mathrm{kcal} / \mathrm{mol}$

function of $\alpha$ and $\beta$ angles. The distance $d$ was set as $3.5 \AA$ as it is generally accepted for $\pi \cdots \pi$ bonding interactions. The angle $\alpha$ was varied from $0^{\circ}$ to $180^{\circ}$ with $30^{\circ}$ increments and $\beta$ was varied from $0^{\circ}$ to $60^{\circ}$ with $10^{\circ}$ increments (for selected $d$, considering higher $\beta$ angles was not necessary as higher $\beta$ angles for that $d$ cause small interatomic distances between the monomers and consequently lead to monomers overlapping). For $\alpha=0^{\circ}$ the directions of the vectors created between the atoms forming the $\mathrm{N}-\mathrm{H}$ bonds (the vector beginnings are the positions of the $\mathrm{N}$ atoms) are the same. These calculations were then repeated with the selected density functionals based on the literature data $[49,52,58,59]$. Two of them were dispersion-corrected DFT functionals comprising B97-D3 and $\omega$ B97XD [60]. Both B97-D3 and $\omega$ B97XD have been shown to describe the intermolecular interactions in the systems involving the interactions between the aromatic molecules [17, 61]. Apart from these, the popular empirical exchange-correlation density functionals developed by Zhao and Truhlar (M05-2X and M06-2X) [59] have also been selected since they have been shown to describe non-covalent interactions in many systems (also these consisting of aromatic molecules) $[58,59]$. For each method, the calculations were performed using both double- and triple-zeta Dunning's augmented, correlation-consistent basis sets (aug-cc-pVDZ and aug-cc-pVTZ, respectively, aDZ and aTZ hereafter) [55].

On the basis of the obtained data (single point calculations for each system), the contour plots representing energy as a function of $\alpha$ and $\beta$ (Fig. 3) were created using 
Fig. 3 PES maps for the selected pyrrole-pyrrole model systems $\left(d=3.5 \AA, \gamma=0^{\circ}\right)$ obtained by the use of selected methods: M05-2X (a), M06-2X (b), $\omega \mathrm{B} 97 \mathrm{XD}(\mathbf{c})$ and $\mathrm{B} 97-\mathrm{D} 3$

(d). aDZ and aTZ stand for augcc-pVDZ and aug-cc-pVTZ basis sets, respectively

\section{Interaction energies (kcal/mol)}
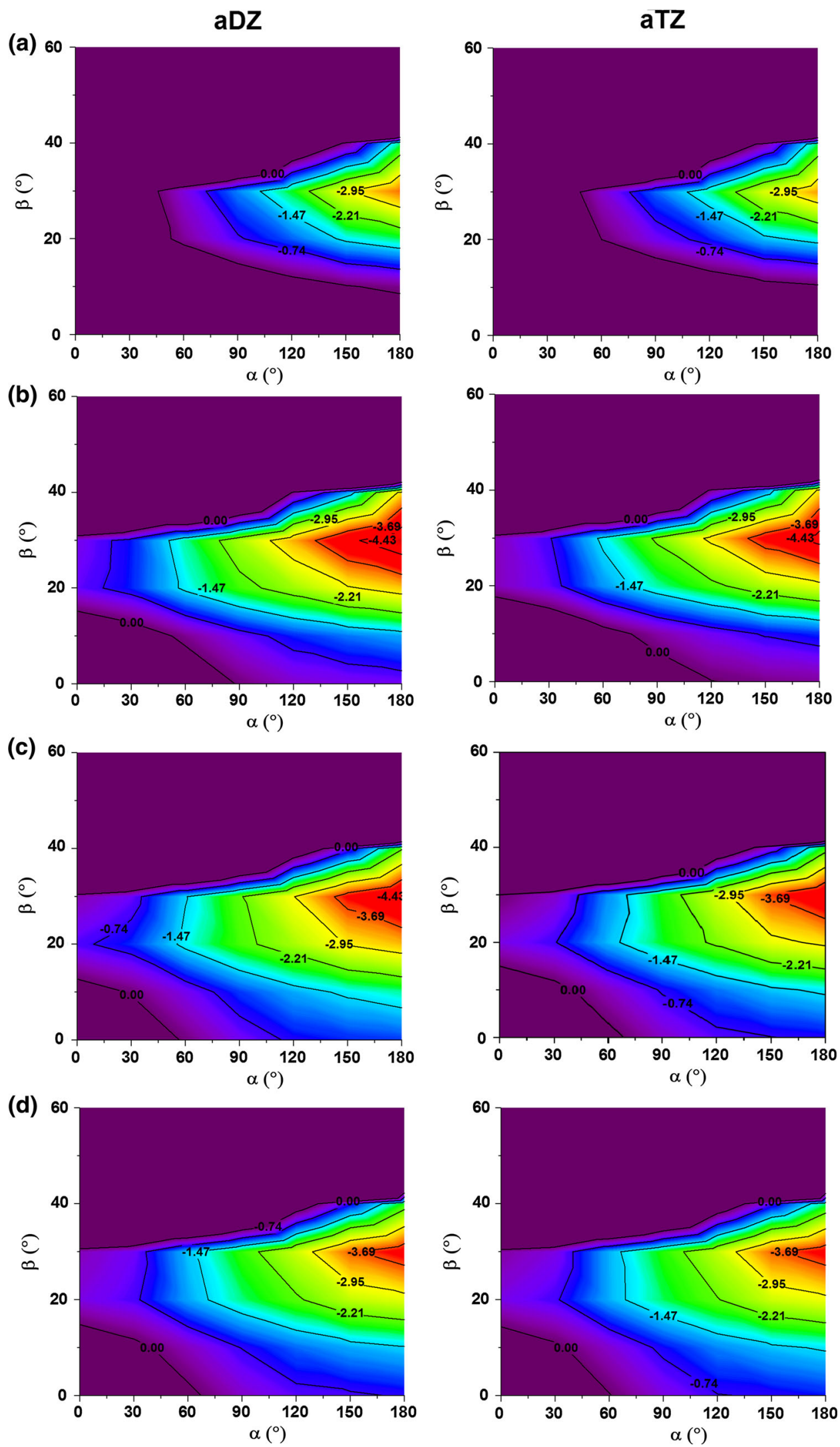
OriginPro 2015 [62]. In general, the system's smallest energies were found for $\beta=30^{\circ}$. For this $\beta$ value, curves representing the energy as a function of $\alpha$ parameter were made (Fig. 4). Interaction energy values that were used to create the curves were used to quantitatively compare the selected methods. According to the performed calculations (Figs. 2, 3, 4), the most suitable DFT method appeared to be B97-D3 with aDZ. This functional allowed to obtain very good results with relatively small computational effort (see further text for more details) and was selected, together with aDZ basis set, for performing all further calculations allowing to obtain PES as a function of $d, \alpha, \beta$ and $\gamma$ parameters (Fig. 1). In these calculations, $\alpha$ was varied from $0^{\circ}$ to $330^{\circ}$ with $30^{\circ}$ increments, $\beta$ was varied from $0^{\circ}$ to $90^{\circ}$ with $10^{\circ}$ increments, $d$ was varied from 3 to $7 \AA$ with $0.25 \AA$ increments and $\gamma$ was varied from $0^{\circ}$ to $180^{\circ}$ with $45^{\circ}$ increments. Because of the dimer system symmetry, taking into account higher $\gamma$ values was not necessary. For $\gamma=0^{\circ}$, the lateral shifting (associated with the increase in $d$ values at the given $\beta$ ) of one ring along the plane of the other was in accordance with the direction of the vector created between the other ring centroid and the nitrogen atom of this ring (the vector beginning was the position of the ring centroid).

In order to find possible orbital interactions between the monomers in the studied dimers (e.g. associated with the creation of $\mathrm{N}-\mathrm{H} \cdots \pi$ bond(s)), the electronic properties of the model dimer pyrrole systems with the energies corresponding to the energy minima on the PES maps (the global energy minimum and the selected local minima, Fig. 5)

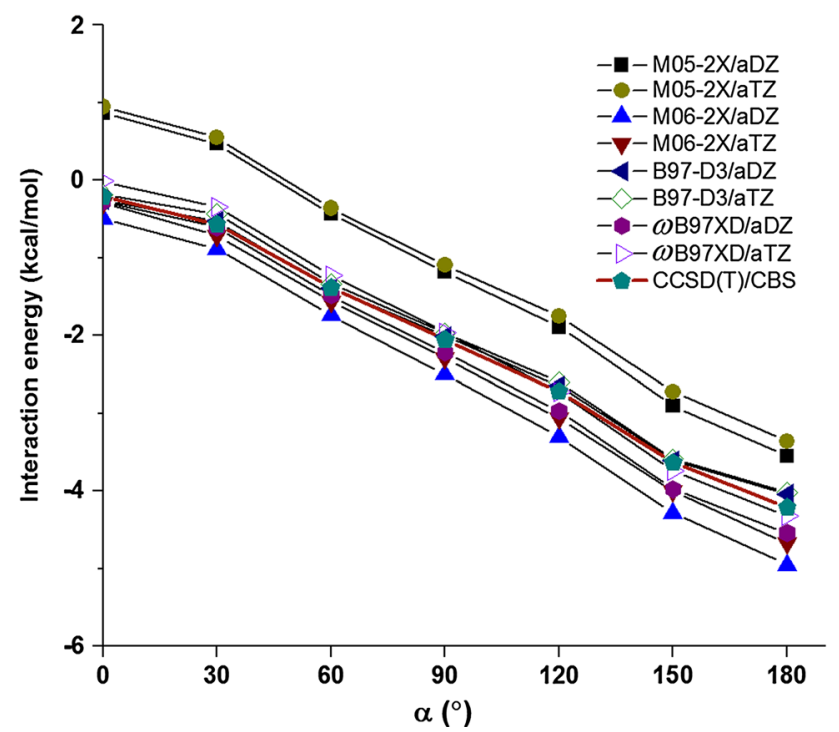

Fig. 4 Interaction energy curves created on the basis of data obtained for the selected pyrrole dimer systems $\left(\gamma=0^{\circ}, d=3.5 \AA\right.$ and $\beta=30^{\circ}$ ). aDZ and aTZ stand for aug-cc-pVDZ and aug-cc-pVTZ basis sets, respectively were characterised in terms of natural bond orbital (NBO) [63-65] analysis at MP2/aTZ level of theory. Those dimer systems were also analysed (at MP2/aTZ level of theory) in terms of recently developed $\mathrm{Hu}, \mathrm{Lu}$, and Yang (HLY) charge-fitting method [66] which happened to give better results than commonly accepted CHelpG [67] scheme.

The B97-D3/aDZ energies of a benzene dimer (BBD), pyridine dimer (PPD) and benzene-pyridine system (BPD), whose geometries (associated with the energy minima of these systems) were taken from the S22 [68] (for BBD) and S66 sets [69] (for PPD and BPD), were calculated to compare them with the one found for a pyrrole dimer system. The HLY charges and the electrostatic potential surfaces (EPS) of benzene and pyridine molecules were also calculated-with the electron density obtained at MP2/aTZ level of theory. All the molecule geometries were optimised at MP2/aDZ level.

Intermolecular interactions in the pyrrole-pyrrole systems, whose geometries correspond to the found global and local energy minima (Fig. 6), along with intermolecular interactions in BBD, BPD and PPD were analysed by means of localised molecular orbital energy decomposition analysis (LMO-EDA) [70]. This is a relatively new and robust energy decomposition method (though like many other methods of this kind it is still computationally demanding [70]), and it can be considered as an extension and modification of the methods developed by Kitaura and Morokuma [71], Ziegler and Rauk [72] and Hayes and Stone [73]. It allows to learn about the interaction nature in a system, and since its implementation in GAMESS software package [74, 75], it has been successfully used to study the intermolecular interactions (e.g. hydrogen bonds, $\pi \cdots \pi$ and $\mathrm{C}-\mathrm{H} \cdots \pi$ contacts) in many different systems such as indole-cation-anion complexes [76], aromatic units of amino acids with guanidinium cation [77], hydrogen-bonded complexes of serotonin [78], radical-conjugated systems [79] and $\mathrm{C}-\mathrm{H} / \pi$ complexes in water [80]. In this method, the interaction energy is decomposed to electrostatic $\left(E^{\mathrm{ele}}\right)$, exchange $\left(E^{\mathrm{ex}}\right)$, repulsion $\left(E^{\mathrm{rep}}\right)$ and polarization $\left(E^{\text {pol }}\right)$ terms, and they are calculated on the basis of single-determinant Hartree-Fock (HF) wave functions. The correlation term $\left(E^{\mathrm{corr}}\right)$, roughly dispersion, is derived from a supermolecule approach by the use of correlation methods (e.g. MP2), and it equals to the difference between the correlation method energy and HF energy [70]. In this work, the contribution of correlation energy was estimated from B97-D3/aDZ calculations-the $\mathrm{E}^{\text {corr }}$ was calculated as a difference between the B97-D3/aDZ energy and HF/ aDZ energy. The LMO-EDA calculations were made using GAMESS [74, 75] software employing HF/aDZ method. In the LMO-EDA calculation, as implemented in GAMESS, the counterpoise correction for basis set superposition error is used. 
Fig. 5 PES maps of the studied pyrrole dimer systems (on the left) together with the maps depicting the corresponding aromatic ring centre distances (on the right). The PES maps were created on the basis of energy minima found for the systems with the given $\alpha$ and $\beta$ values
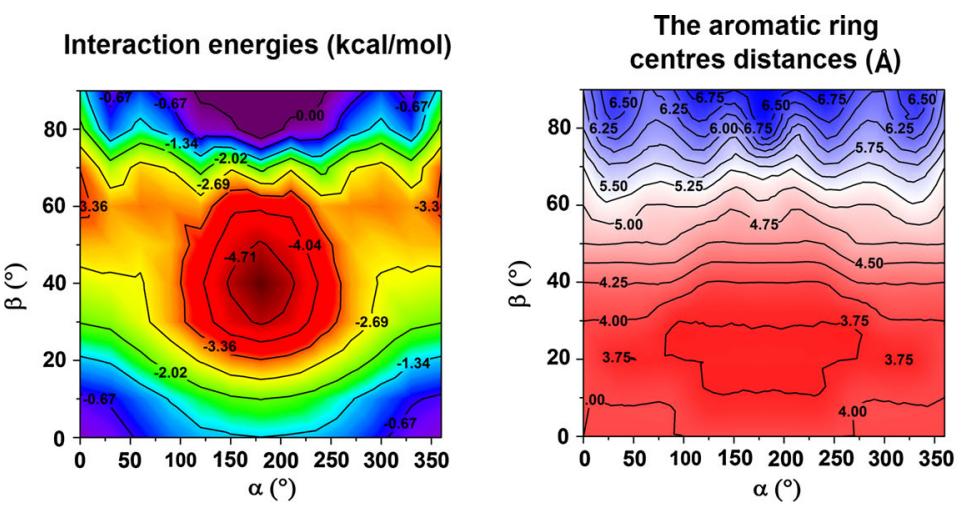

$\gamma$ values $\left({ }^{\circ}\right)$
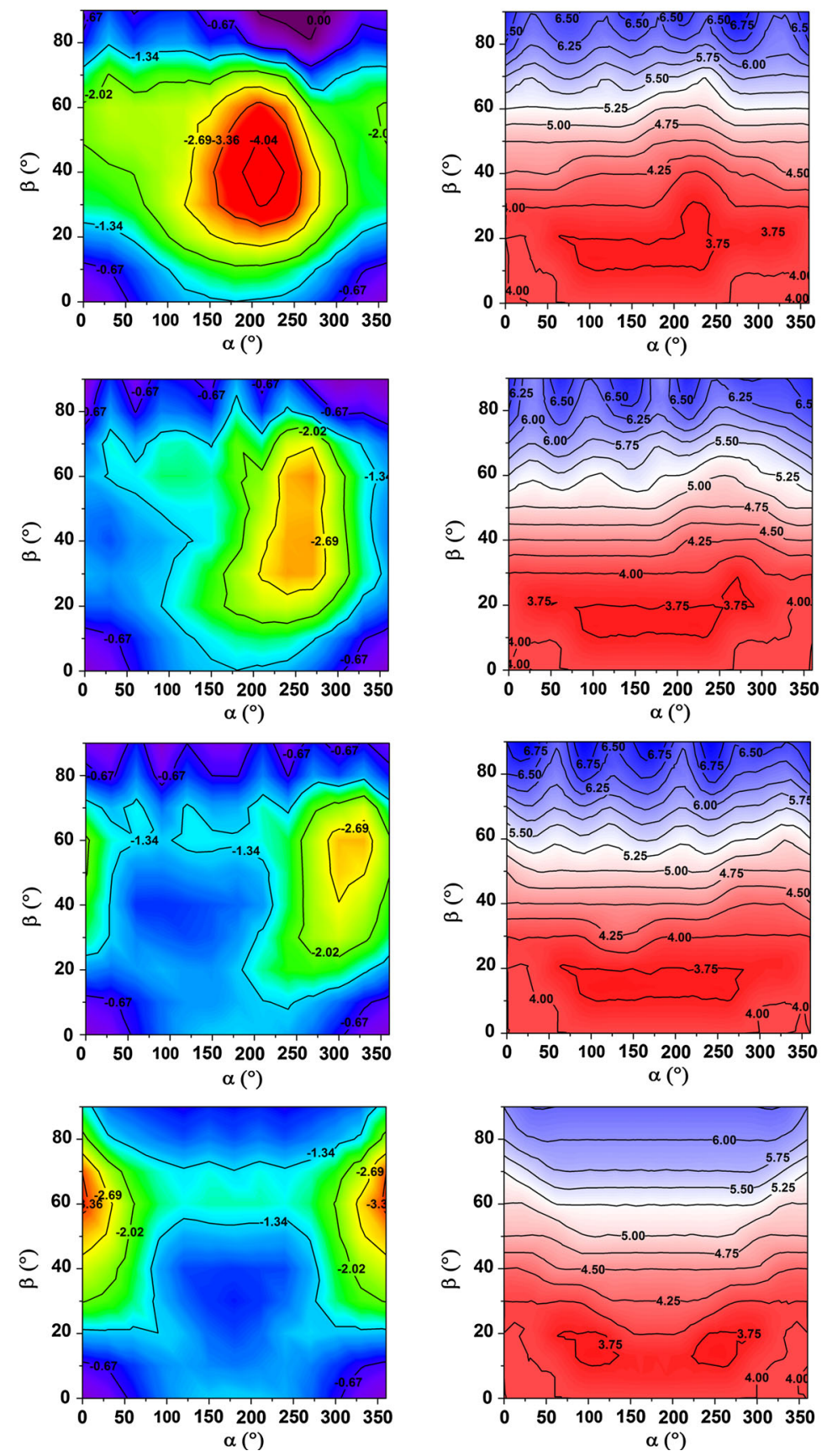

45

90

0

135

180 


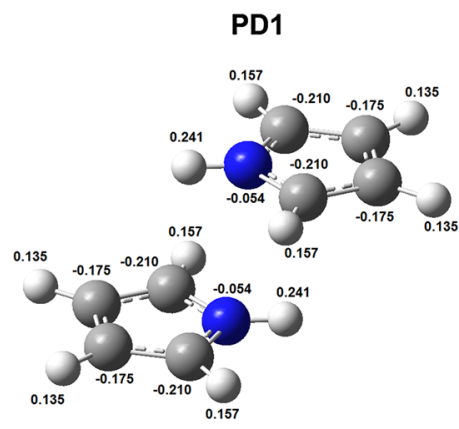

PD4

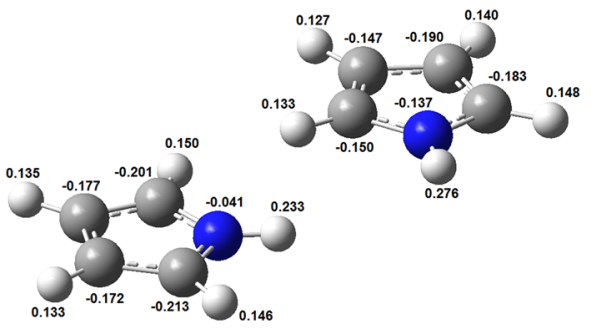

PD2

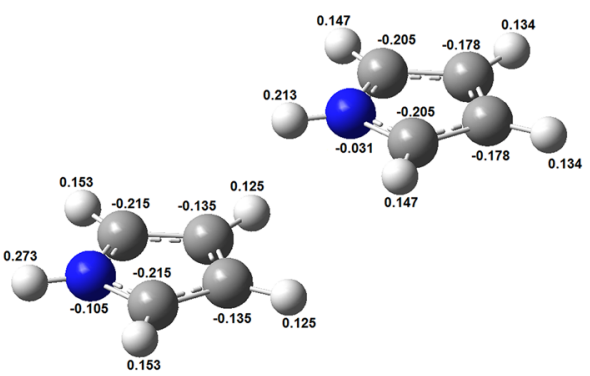

PD5
PD3

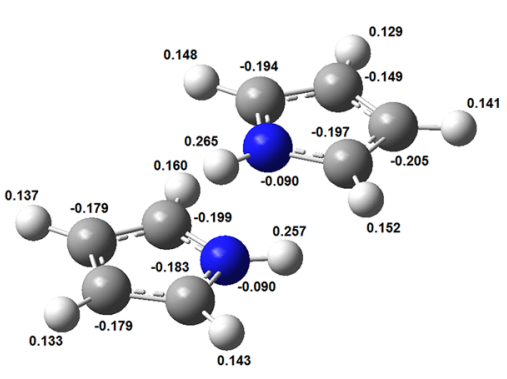

PD6
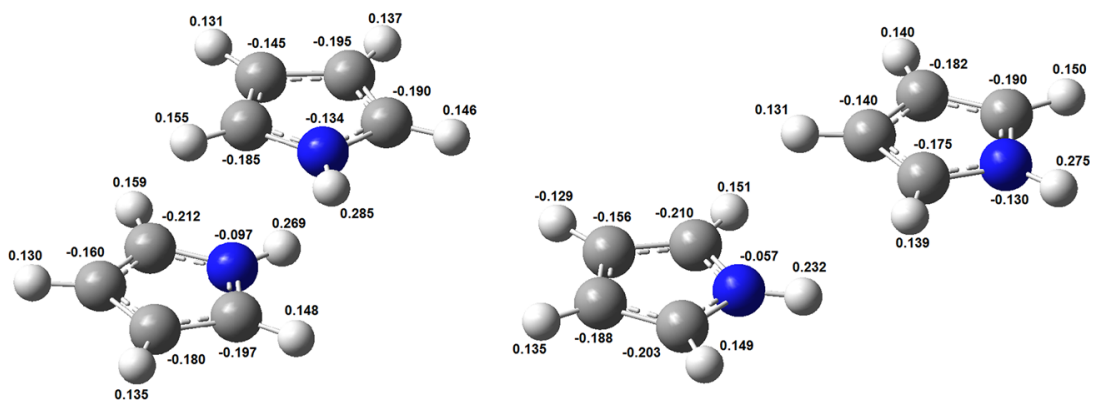

Fig. 6 Geometries of the pyrrole-pyrrole systems that are associated with the found energy minima, together with the atom HLY charge values (e)

\section{Results and discussion}

Among the tested methods, M05-2X gave the poorest results. The use of this density functional gave similar results with both double- and triple-zeta basis sets with mean deviations from $\operatorname{CCSD}(\mathrm{T}) / \mathrm{CBS}$ results equal to $0.88 \mathrm{kcal} / \mathrm{mol}$ and $1.00 \mathrm{kcal} / \mathrm{mol}$, respectively, for $\mathrm{aDZ}$ and aTZ (Figs. 3a, 4). It must be noted, however, that though M05-2X energies deviate relatively much from those obtained from $\operatorname{CCSD}(\mathrm{T}) / \mathrm{CBS}$, the general energy dependencies between these two are similar. Nevertheless, because of this relatively large underestimation in binding energy, using M05-2X density functional, one should be aware of the possibility of formulation of inappropriate conclusions since among the tested methods in case of M05-2X the binding ranges are clearly the smallest (Fig. 3). The use of M06-2X allowed to obtain much better results compared with those from M05-2X. Unlike in case of M05-2X, the obtained interaction energy values are more basis-set-dependent and when compared with the reference method appeared to be slightly overestimatedby around -0.48 and $-0.26 \mathrm{kcal} / \mathrm{mol}$, respectively, for aDZ and aTZ (Figs. 3b, 4). The resulting computational time ratio for the above methods is 1:15.1:1.4:18.6:147.8, where the values correspond to M05-2X/aDZ, M05-2X/
aTZ, M06-2X/aDZ, M06-2X/aTZ and the reference CCSD(T)/CBS, respectively.

The results based on the selected dispersion-corrected density functionals were similar to each other and appeared to be better from those developed by Zhao and Truhlar (M05-2X and M06-2X). The mean energy deviation values from the reference $\mathrm{CCSD}(\mathrm{T}) / \mathrm{CBS}$ method were very small, and they were within the range of $0.06-0.18 \mathrm{kcal} / \mathrm{mol}$ (Figs. 3c, d, 4). However, it should be noticed that the values obtained from B97-D3 were less basis-set-dependent, while in case of $\omega \mathrm{B} 97 \mathrm{XD}$ the difference between the found energy values employing aDZ and aTZ basis sets is seen a bit clearer. $\omega \mathrm{B} 97 \mathrm{XD}$ gave better results with aTZ basis set and they are comparable to those from B97-D3/ $\mathrm{aDZ}$ and B97-D3/aTZ (Fig. 4). The computational cost was the lowest in case of B97-D3/aDZ resulting in the computational time ratio $1: 8.8: 3.2: 28.8: 257.7$, where the values correspond to B97-D3/aDZ, B97-D3/aTZ, $\omega$ B97XD/aDZ, $\omega \mathrm{B} 97 \mathrm{XD} / \mathrm{aTZ}$ and the reference $\mathrm{CCSD}(\mathrm{T}) / \mathrm{CBS}$, respectively. Considering the above, the B97-D3 employing aDZ, which gave excellent results with relatively low computational cost, appeared to be the most suitable DFT method for further calculations.

The performed energy scans allowed to create PES surfaces on which basis the optimal configurations of the 
pyrrole ring system can be identified (with the given resolution). The found energy minima are rather broad, and this enables a certain degree of flexibility in the system configuration.

In all cases, the minimum $d$ that was set as $3 \AA$ is too small for providing binding interaction energies, and the optimal $d$ value appeared to be $4 \AA$ (Fig. 7). However, for specific geometries, the binding interactions are observed even for much larger $d$-up to $7 \AA$. It is noticed that with the increase in $d$, the maximum binding energy for that $d$ are observed for configurations with higher $\beta$ angle (Fig. 7). It seems to be associated with the maximization of the dispersion and binding electrostatic interactions as a higher $\beta$ angle forces the decrease in the distance between two interacting molecules. The analysis of $\alpha$ and $\gamma$ angles confirms this assumption. The pyrrole molecules in the interacting dimers are oriented to minimize the electrostatic repulsion, e.g. in most cases the optimal $\alpha$ is $180^{\circ}$ (Fig. 7). Changing of the $\gamma$ angle is not energetically favourable unless this change leads to symmetrically equivalent geometry. Some system configurations for $\gamma$ being equal to $0^{\circ}$ and $180^{\circ}$ are symmetrically equivalent.

For all $\gamma$ values, the energy minima were found for systems in a parallel-displaced (PD) configuration. In this geometry, the pyrrole molecules are in the arrangements in which there seem to be an optimal balance between the electrostatic and dispersion forces. The system global energy minimum was found for $\gamma=0^{\circ}$ (Fig. 5). This minimum corresponds to the dimer configuration in which the twist angle $(\alpha)$ between the monomers is equal to $180^{\circ}$. In this arrangement, the directions of the vectors created between the atoms forming the $\mathrm{N}-\mathrm{H}$ bonds (the vector beginnings are the positions of the $\mathrm{N}$ atoms) are opposite to each other (Fig. 6). For this PD configuration (PD1), the $\beta=40^{\circ}$ and $d=4 \AA$. The interaction energy associated with this system geometry is equal to $-5.38 \mathrm{kcal} / \mathrm{mol}$. This value is relatively large (in binding terms), and it is higher than the one found for BBD. For BBD, the B97-D3/aDZ interaction energy is equal to $-3.47 \mathrm{kcal} / \mathrm{mol}$. For PPD, the interaction energy calculated at B97-D3/aDZ level of theory is equal to $-4.53 \mathrm{kcal} / \mathrm{mol}$, and for BPD, the B97-D3/ $\mathrm{aDZ}$ interaction energy is equal to $-4.08 \mathrm{kcal} / \mathrm{mol}$. The differences in the binding interaction energies of these systems seem to be associated with the differences in the charge distribution of the interacting molecules. This matter is addressed further in the text.

In case of $\gamma=0^{\circ}$, a second energy minimum can be distinguished. For the dimer geometry associated with this minimum (PD2), the $\alpha=0^{\circ}$ and $\beta=60^{\circ}$. In this configuration, the directions of both vectors created between the atoms forming the $\mathrm{N}-\mathrm{H}$ bonds (the vector beginnings are the positions of the $\mathrm{N}$ atoms) are the same (Fig. 6). The distance between both the ring centroids is larger than it is for PD1 geometry, and it equals to $5 \AA$.

For higher $\gamma$ values, the calculated interaction energy values, in general, are higher (smaller in the binding terms) than those observed for dimer geometries with $\gamma=0^{\circ}$ (Table 1). As it is observed, for systems with higher $\gamma$ values, it is energetically favourable to increase the $\alpha$ angle which leads to minimization of the electrostatic repulsion (Figs. 5, 6). In case of $\gamma=45^{\circ}$, the PES of the studied pyrrole dimer system is simpler with only one energy minimum observed. The system configuration associated with this minimum (PD3) is similar to PD1. The only difference is a little higher $\alpha$ angle value (Table 1). With the increase in $\gamma$, the PES of the pyrrole dimer system is getting more complex. For $\gamma=90^{\circ}$, two energy minima are found. One of them is associated with the dimer configuration (PD5) in which the $d$ distance is $4 \AA$ (the same as it is in case of PD1 and PD3). The $\alpha$ angle for PD5 is higher than it is for formerly discussed geometries (Table 1). The second energy minimum for this $\gamma$ value is related to a dimer configuration (PD4) with longer $d$ distance and with higher $\alpha$ and $\beta$ angle values (Table 1). For both $\gamma=135^{\circ}$
Fig. 7 PES maps of the studied pyrrole dimer systems (on the left) along with the maps depicting the corresponding $\alpha$ angle values $\left(^{\circ}\right)$ (on the right). The PES maps were created on the basis of energy minima ( $\mathrm{kcal} / \mathrm{mol}$ ) found for the systems with the given $d$ and $\beta$ values
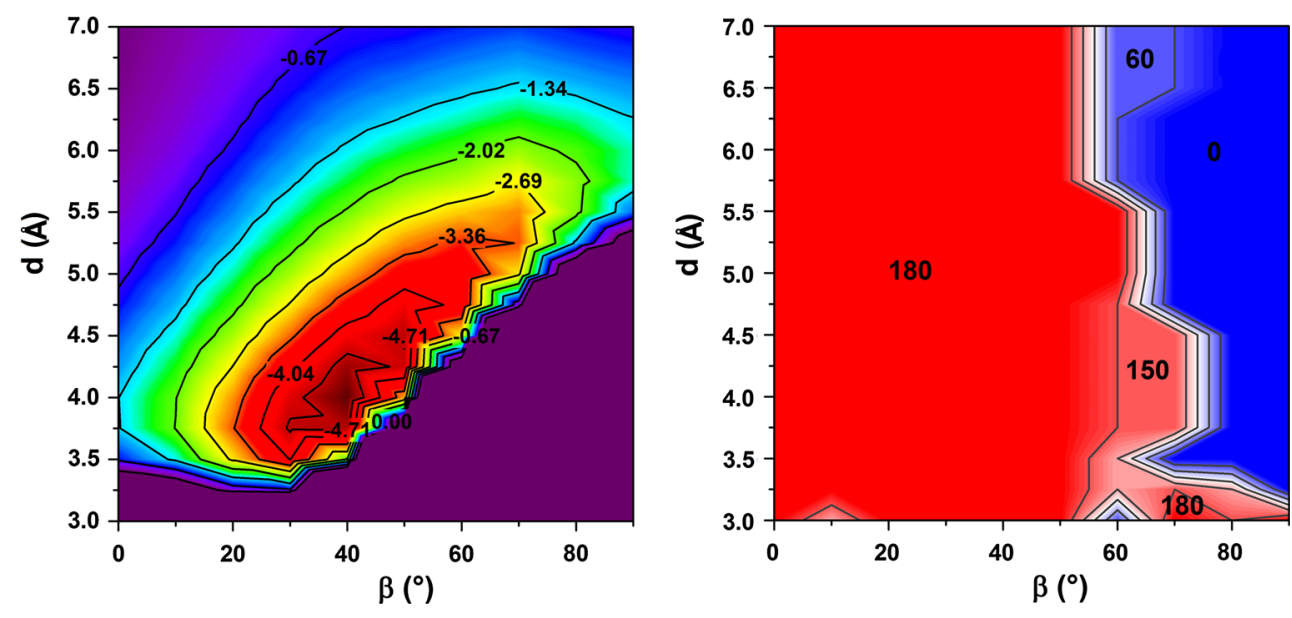
Table 1 Geometrical parameters, interaction energy values and NBO data related to the pyrrole dimer configurations associated with the energy minima found on the created PES maps

\begin{tabular}{llllllll}
\hline $\begin{array}{l}\text { Pyrrole dimer } \\
\text { configuration }\end{array}$ & $\begin{array}{l}\alpha \text { angle } \\
\left({ }^{\circ}\right)\end{array}$ & $\begin{array}{l}\beta \text { angle } \\
\left({ }^{\circ}\right)\end{array}$ & $\begin{array}{l}\gamma \text { angle } \\
\left({ }^{\circ}\right)\end{array}$ & $\begin{array}{l}d \text { distance } \\
(\AA)\end{array}$ & $\begin{array}{l}\text { Rydberg orbitals } \\
\text { contribution }(\%)\end{array}$ & $\begin{array}{l}\text { Non-Lewis density } \\
\text { participation }(\%)\end{array}$ & $\begin{array}{l}\text { Interaction energy value } \\
(\mathrm{kcal} / \mathrm{mol})\end{array}$ \\
\hline PD1 & 180 & 40 & 0 & 4 & 1.06 & 3.94 & -5.38 \\
PD2 & 0 & 60 & 0 & 5 & 1.05 & 3.94 & -3.53 \\
PD3 & 210 & 40 & 45 & 4 & 1.06 & 3.94 & -4.35 \\
PD4 & 270 & 60 & 90 & 5 & 1.05 & 3.94 & -3.12 \\
PD5 & 240 & 30 & 90 & 4 & 1.06 & 3.94 & -3.06 \\
PD6 & 330 & 60 & 135 & 5 & 1.05 & 3.93 & -2.98 \\
\hline
\end{tabular}

and $\gamma=180^{\circ}$, only one energy minimum is found. This minimum is associated with the respective dimer geometries: PD6 and PD2 (Fig. 6). In case of these system configurations, the $d=5 \AA$. Longer $d$ distance forces the increase in $\beta$ angle to make the binding interaction stronger (Table 1). The interaction energy in case of PD6 is the highest one (Table 1), but compared with system geometries related to energy minima for the respective $\gamma$ being equal to $90^{\circ}$ and $180^{\circ}$, the differences are relatively small and all the interaction energy values are comparable. For $\gamma=180^{\circ}$, the sole energy minimum is associated with the system geometry that is symmetrically equivalent to PD2.

The system configurations (Fig. 6) that are associated with the energy minima mentioned above may suggest that the particular interactions between monomers result mainly from the creation of an $\mathrm{N}-\mathrm{H} \cdots \pi$ bond(s). However, the NBO analysis performed for all those system geometries did not show any dominant orbital interactions. Hence, it can be stated that the short-range interactions, associated with the overlap of the molecular orbitals, are not the major source of the interactions between the monomers. Both in the single monomer and in dimers, the contribution of electron density associated with Rydberg orbitals is relatively large and accounts for around $1.05 \%$ of the system total electron density (Table 1). The NBO analysis emphasizes the importance of non-Lewis density participation (valence-shell antibonds density and Rydberg orbitals density) with its contribution of around $4 \%$ (Table 1).

The changes in the intermolecular interaction energy values in the above-described pyrrole dimers are explained by the monomer arrangements and LMO-EDA. The B97D3/aDZ and LMO-EDA calculations show that the participation of the $E^{\text {corr }}$ into the intermolecular interaction is the greatest (the smallest energy values) in PD1, PD3 and PD5 (Table 2). In those systems, the $d$ distances are the shortest and the $\beta$ angles the smallest (Table 2). Hence, the monomers in these systems are further to co-planarity than in PD2, PD4 and PD6, which increases the monomer interaction surfaces. The $E^{\mathrm{ele}}$ and $E^{\mathrm{pol}}$ values are the lowest in case of PD1 and PD3 (Table 2). It is explained by the specific $\alpha$ angle values (Table 2). These $\alpha$ angles, together with relatively short $d$ distances and small $\beta$ angles, make it possible for both the $\mathrm{N}-\mathrm{H}$ bonds (polar ones) presented in the system being in a direct interaction with a second monomer. Though the sums of the $E^{\mathrm{ex}}$ and the $E^{\mathrm{rep}}$ are the largest for PD1 and PD3 systems, the relatively high $E^{\text {ele }}$, $E^{\text {pol }}$ and $E^{\text {corr }}$ contributions add up enough binding energy to the total interaction energies in those systems to make these interactions the strongest (Table 2).

The EPS of a pyrrole molecule shows that this molecule is relatively highly polarised (Fig. 8). It is particularly observed for $\mathrm{C}-\mathrm{H}$ and $\mathrm{N}-\mathrm{H}$ bonds. The charge analysis based on the HLY charge-fitting method shows (Fig. 8) that the nitrogen atom and all the carbon atoms of a pyrrole molecule are negatively charged, while the positive charge is located on hydrogen atoms. Analogues situation is found for a benzene molecule (Fig. 8). However, in case of it, the charge separation is smaller. This may help to explain the differences in the interaction energies observed for the benzene-benzene dimer and the studied pyrrole-pyrrole system. Most likely due to these charge distribution differences, the binding interaction energy of the benzenebenzene system is smaller than it is for the pyrrole dimer. The binding interaction energy of the pyrrole dimer appeared to be even greater (a smaller negative value) than the one calculated for the pyridine dimer. In a pyridine molecule, the charge separation is greater and more complex, with nitrogen and some carbon atoms being negatively charged and some carbon atoms being positively charged (Fig. 8). The calculated dipole moment of a pyridine molecule is also slightly higher than the one calculated for a pyrrole molecule (Fig. 8). However, in a pyrrole molecule, the positively charged hydrogen atom of the $\mathrm{N}-$ $\mathrm{H}$ bond seems to make it possible for pyrrole molecules to arrange in a way for which the negative molecule repulsion is minimised in a greater degree than it is in case of pyridine molecules (Fig. 6). The charge distribution in an interacting pyrrole molecule (involved in a dimer system) 
Table 2 LMO-EDA decomposed energy terms $(\mathrm{kcal} / \mathrm{mol})$ (a)

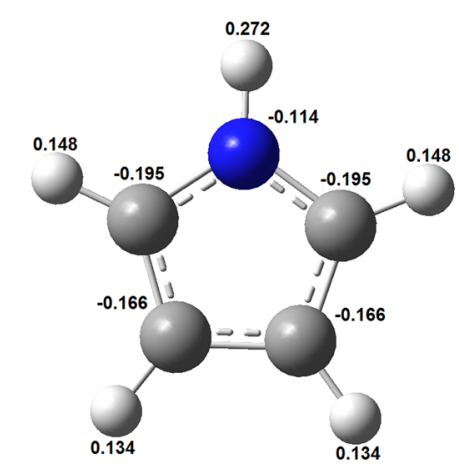

(b)

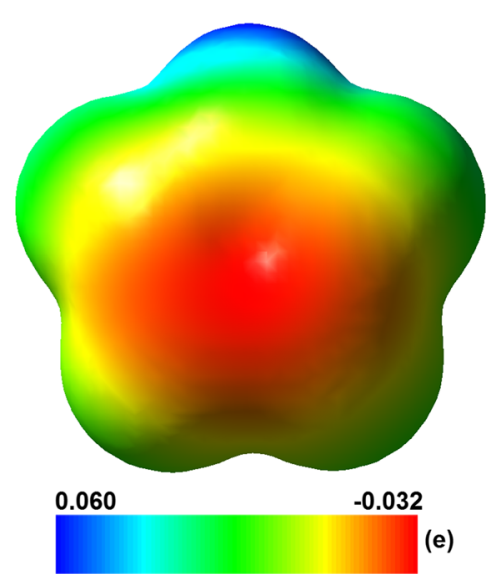

Benzene
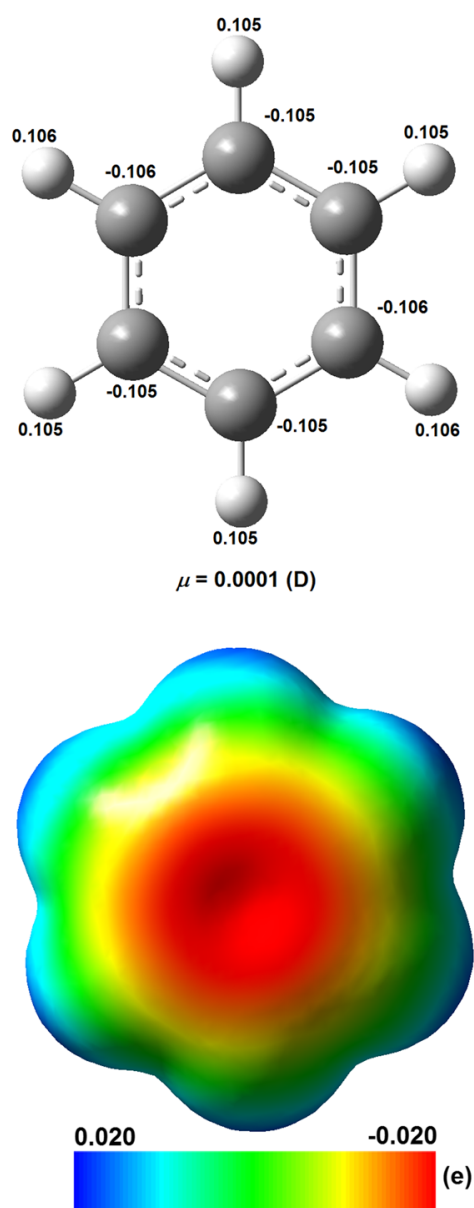

Pyridine

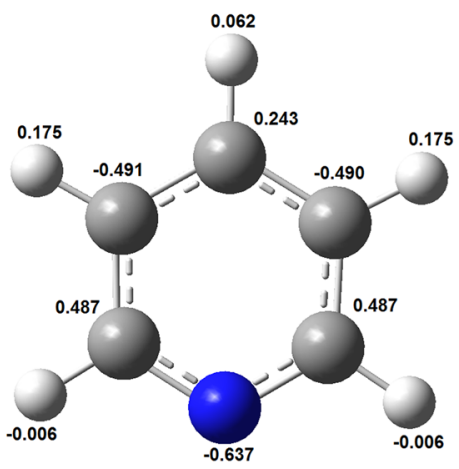

$\mu=2.3258$ (D)

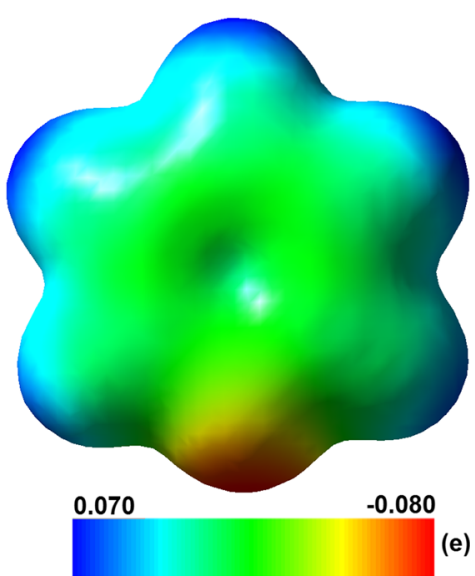

Fig. 8 Atom HLY charge values (e) (a) and EPS maps (b) calculated for benzene, pyridine and pyrrole molecule. The EPS maps are superimposed on the isodensity surface $\left(0.005 \mathrm{e} / \AA^{3}\right)$

is slightly different than in case of a non-interacting one. It is especially seen for an $\mathrm{N}-\mathrm{H}$ bond in which electron density is altered when it approaches a second pyrrole monomer which leads to the decrease in its polarity (Figs. 6, 8). For an $\mathrm{N}-\mathrm{H}$ bond that is not in a direct interaction with a second monomer, its polarity is almost not affected (e.g. the configuration PD2, Figs. 6, 8). The observed charge distribution differences (a benzene molecule $v s$ a pyridine molecule $v s$ a pyrrole molecule) underline the importance of the electrostatic factor in the intermolecular interactions. In a consequence, this leads to a conclusion saying that the significant source of the 


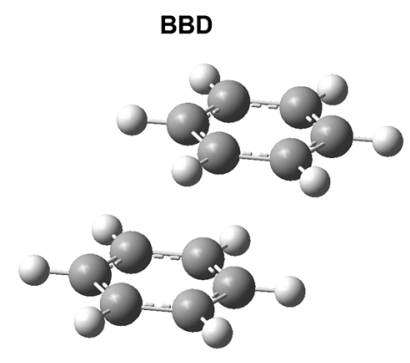

- $3.47 \mathrm{kcal} / \mathrm{mol}$

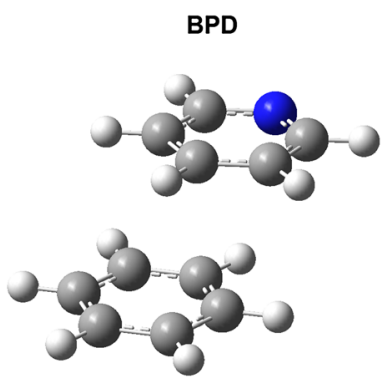

$-4.08 \mathrm{kcal} / \mathrm{mol}$
PPD
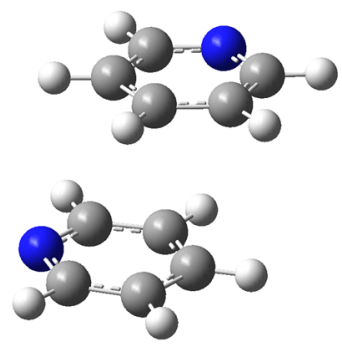

$-4.53 \mathrm{kcal} / \mathrm{mol}$
PD1

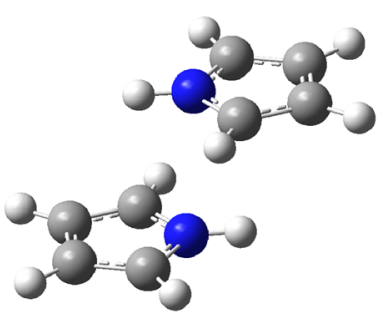

$-5.38 \mathrm{kcal} / \mathrm{mol}$

electrostatic

London dispersion forces

Fig. 9 Geometries of benzene-benzene, benzene-pyridine, pyridine-pyridine and pyrrole-pyrrole dimers that are associated with the energy minima of these systems (for parallel-displaced configurations)

interaction in the studied pyrrole dimers is the electrostatic interaction between the monomers. Hence, the significance of the contribution of London dispersion forces is the highest in case of BBD and the smallest in PD1 (Fig. 9). This claim is validated by the energy decomposition analysis (Table 2). It shows that the contribution of $E^{\text {corr }}$ (binding energy term) changes as follows: $\mathrm{BBD}>\mathrm{PPD} \approx \mathrm{BPD}>\mathrm{PD} 1$. The LMO-EDA reveals that the $E^{\text {ele }}$ in PD1 is significantly lower than it is in BBD, PPD and BPD, and thus, it encourages the PD1 monomers to bind stronger. The sums of $E^{\text {ex }}$ and $E^{\text {rep }}$ (positive in all cases) change according to the following dependency: $\mathrm{BBD}>\mathrm{PPD}>\mathrm{BPD}>\mathrm{PD} 1$. The role of $E^{\mathrm{pol}}$ is similar in all these systems, and it contributes about $-1 \mathrm{kcal} / \mathrm{mol}$ to the total intermolecular interaction energy (Table 2).

\section{Conclusion}

Both B97-D3 and $\omega$ B97XD density functionals are capable of describing the intermolecular interactions in the studied pyrrole ring systems. However, the B97-D3, at least in this case, is less basis-set-dependent and much faster than $\omega$ B97XD. The M06-2X with aTZ performed slightly worse, but considering relatively small deviations from the reference CCSD/CBS, its results can be consider as satisfactory.

The "sandwich" ring system configuration $\left(\beta=0^{\circ}\right)$ is not associated with any energy minimum (Figs. 5, 6). Hence, this conformation is not energetically favourable and should not be arbitrarily used in studies of $\pi \cdots \pi$ interactions. This is in accordance with the study made for other systems [17, 81].

With the used resolution, the optimal ring centroid distance was found to be $4 \AA$ and the optimal twist angle $(\alpha)$ is equal to $180^{\circ}$. However, the bonding geometry boundaries are relatively broad, and the stacking interactions can be binding even for ring centroid distances larger than $6 \AA$, provided that the stacked rings are in an appropriate geometry. Recently, the same has been observed for sixmembered aromatic ring systems [81-83].

The importance of non-Lewis density participation (valence-shell antibonds density and Rydberg orbitals density) in the studied systems is emphasised. The intermolecular interaction of the pyrrole-pyrrole systems cannot be described in a simple orbital term, and the observed interactions should be considered as electrostatic and dispersion ones.

Except for the relatively small contribution of correlation energy, the pyrrole-pyrrole system interaction energy appeared to be lower than those found for benzene-benzene, benzene-pyridine and pyridine-pyridine configurations. The corresponding B97-D3 interaction energy values are equal to $-5.38 \mathrm{kcal} / \mathrm{mol},-3.47 \mathrm{kcal} / \mathrm{mol},-4.08 \mathrm{kcal} / \mathrm{mol}$ and $-4.53 \mathrm{kcal} / \mathrm{mol}$ for pyrrole-pyrrole, benzene-benzene, benzene-pyridine and pyridine-pyridine, respectively. The specific charge distribution in a pyrrole molecule and its relatively high polarization are the main source of the binding intermolecular interaction in pyrrole dimer systems. However, the importance of London dispersion forces must not be neglected.

It is presumed that the presented results will shed more light on stacking interaction phenomenon and lead to a deeper understanding of its role (e.g. in biological systems and crystal engineering). The presented PES maps (Fig. 5) can be used as a guide for qualitative predictions of the existence of the binding interactions and may inspire other researchers to engage in gaining further insight into NCI phenomenon. 
Acknowledgments Young Scientists' Fund at the Faculty of Chemistry, Lodz University of Technology, Grant W-3/FMN/12G/ 2015. The Gaussian 09 calculations were carried out in the Academic Computer Centre ACK CYFRONET of the University of Science and Technology (AGH) in Cracow, Poland, under Grant No. MNiSW/ IBM_BC_HS21/PŁódzka/041/2014.

Open Access This article is distributed under the terms of the Creative Commons Attribution 4.0 International License (http://crea tivecommons.org/licenses/by/4.0/), which permits unrestricted use, distribution, and reproduction in any medium, provided you give appropriate credit to the original author(s) and the source, provide a link to the Creative Commons license, and indicate if changes were made.

\section{References}

1. Wang C, Guan L, Danovich D, Shaik D, Mo Y (2015) The origins of the directionality of noncovalent intermolecular interactions. J Comput Chem. doi:10.1002/jcc.23946

2. Zhang Y, Lu Y, Xu Z, Ding H, Wu W, Liu H (2015) Intramolecular halogen bonds in 1,2-aryldiyne molecules: a theoretical study. Struct Chem. doi:10.1007/s11224-015-0671-z

3. Raynal M, Ballester P, Vidal-Ferranab A, van Leeuwen PWNM (2014) Supramolecular catalysis. Part 1: non-covalent interactions as a tool for building and modifying homogeneous catalysts. Chem Soc Rev 43:1660-1733

4. Li GY, Guan RL, Ji LN, Chao H (2014) DNA condensation induced by metal complexes. Coord Chem Rev 281:100-113

5. Johnson ER, Keinan S, Mori-Sanchez P, Contreras-Garcia J, Cohen AJ, Yang W (2010) Revealing noncovalent interactions. J Am Chem Soc 132:6498-6506

6. Burley SK, Petsko GA (1985) Aromatic-aromatic interaction: a mechanism of protein structure stabilization. Science 229:23-28

7. Panini P, Chopra D (2012) Role of intermolecular interactions involving organic fluorine in trifluoromethylated benzanilides. Cryst Eng Commun 14:1972-1989

8. Daszkiewicz M (2013) Importance of $\mathrm{O} \cdots \mathrm{N}$ interaction between nitro groups in crystals. Cryst Eng Commun 15:10427-10430

9. Alonso M, Pinter B, Woller T, Geerlings P, De Proft F (2015) Scrutinizing ion- $\pi$ and ion- $\sigma$ interactions using the noncovalent index and energy decomposition analysis. Comput Theor Chem 1053:150-164

10. Robertazzi A, Krull F, Knapp EW, Gamez P (2011) Recent advances in anion- $\pi$ interaction. Cryst Eng Commun 13:3293-3300

11. Schottel BL, Chifotides HT, Dunbar KR (2008) Anion- $\pi$ interactions. Chem Soc Rev 37:68-83

12. Kruszynski R, Sieranski T (2011) The intermolecular interactions in the aminonitromethylbenzenes. Cent Eur J Chem 9:94-105

13. Mohan N, Vijayalakshmi KP, Koga N, Suresh CH (2010) Comparison of aromatic $\mathrm{NH} \pi, \mathrm{OH} \pi$, and $\mathrm{CH} \pi$ interactions of alanine using MP2, CCSD, and DFT methods. J Comput Chem 31:2874-2882

14. Escudero D, Frontera A, Quinonero D, Deya PM (2009) Interplay between anion- $\pi$ and hydrogen bonding interactions. J Comput Chem 30:75-82

15. Tsuzuki S (2005) Interactions with aromatic rings. Struct Bond 115:149-193

16. Rai SK, Srivastava P, Gupta H, Puerta MC, Valerga P, Tewari AK (2015) Unusual reverse face-to-face stacking in propylene linked pyrazole system: perspective of organic materials. Struct Chem 26:555-563
17. Huber RG, Margreiter MA, Fuchs JE, von Grafenstein S, Tautermann CS, Liedl KR, Fox T (2014) Heteroaromatic $\pi$ stacking energy landscapes. J Chem Inf Model 54:1371-1379

18. Mishra BK, Sathyamurthy N (2005) Pi-pi interaction in pyridine. J Phys Chem A 109:6-8

19. Ninkovic DB, Janjic GV, Zaric SD (2012) Crystallographic and ab initio study of pyridine stacking interactions. Local nature of hydrogen bond effect in stacking interactions. Cryst Growth Des 12:1060-1063

20. Wheeler SE, Bloom JWG (2014) Toward a more complete understanding of noncovalent interactions involving aromatic rings. J Phys Chem A 118:6133-6147

21. Gholipour AR, Saydi H, Neiband MS, Neyband RS (2012) Simultaneous interactions of pyridine with substituted benzene ring and $\mathrm{H}-\mathrm{F}$ in $\mathrm{X}$-ben $\perp$ pyr $\mathrm{H}-\mathrm{F}$ complexes: a cooperative study. Struct Chem 23:367-373

22. Li P, Zhao C, Smith MD, Shimizu KD (2013) Comprehensive experimental study of $\mathrm{N}$-heterocyclic $\pi$-stacking interactions of neutral and cationic pyridines. J Org Chem 78:5303-5313

23. Sinnokrot MO, Valeev EF, Sherrill CD (2002) Estimates of the ab initio limit for $\pi-\pi$ interactions: the benzene dimer. J Am Chem Soc 124:10887-10893

24. Zhikol OA, Shishkin OV, Lyssenko KA, Leszczynski J (2005) Electron density distribution in stacked benzene dimers: a new approach towards the estimation of stacking interaction energies. J Chem Phys 122:144104-144111

25. Miliordos E, Apra E (2014) Xantheas SS benchmark theoretical study of the $\pi-\pi$ binding energy in the benzene dimer. J Phys Chem A 118:7568-7578

26. Sinnokrot MO, Sherrill CD (2004) Highly accurate coupled cluster potential energy curves for the benzene dimer: sandwich, T-shaped, and parallel-displaced configurations. J Phys Chem A 108:10200-10207

27. Hobza P, Selzle HL, Schlag EW (1994) Potential energy surface of the benzene dimer: ab initio theoretical study. J Am Chem Soc 116:3500-3506

28. Rodriguez-Ropero F, Casanovas J, Aleman C (2008) Ab initio calculations on $\pi$-stacked thiophene dimer, trimer, and tetramer: structure, interaction energy, cooperative effects, and intermolecular electronic parameters. J Comput Chem 29:69-78

29. Tsuzuki S, Honda K, Azumi R (2002) Model chemistry calculations of thiophene dimer interactions: origin of $\pi$-stacking. J Am Chem Soc 124:12200-12209

30. Wang SF, Guo CL, Cui KK, Zhu YT, Ding JX, Zou XY, Li YH (2015) Lactic acid as an invaluable green solvent for ultrasoundassisted scalable synthesis of pyrrole derivatives. Ultrason Sonochem 26:81-86

31. Bhardwaj V, Gumber D, Abbot V, Dhiman S, Sharma P (2015) Pyrrole: a resourceful small molecule in key medicinal heteroaromatics. RSC Adv 5:15233-15266

32. Weinert EE, Phillips-Piro CM, Marletta MA (2013) Porphyrin $\pi$ stacking in a heme protein scaffold tunes gas ligand affinity. J Inorg Biochem 127:7-12

33. Buchmueller KL, Staples AM, Uthe PB, Howard CM, Pacheco KAO, Cox KK, Henry JA, Bailey SL, Horick SM, Nguyen B, Wilson WD, Lee M (2005) Molecular recognition of DNA base pairs by the formamido/pyrrole and formamido/imidazole pairings in stacked polyamides. Nucleic Acids Res 33:912-921

34. Kopke T, Pink M, Zaleski JM (2006) Photochemical preparation of pyrrole ring-contracted chlorins by the Wolff rearrangement. Org Biomol Chem 4:4059-4062

35. ó Proinsias K, Giedyk M, Gryko D (2013) Vitamin B12: chemical modifications. Chem Soc Rev 42:6605-6619

36. Ryan AA, Senge MO (2015) How green is green chemistry? Chlorophylls as a bioresource from biorefineries and their 
commercial potential in medicine and photovoltaics. Photochem Photobiol Sci 14:638-660

37. Kim SB, Chang BY, Hwang BY, Kim SY, Lee MK (2014) Pyrrole alkaloids from the fruits of Morus alba. Bioorg Med Chem Lett 24:5656-5659

38. Lansdell TA, Hewlett NM, Skoumbourdis AP, Fodor MD, Seiple IB, Su S, Baran PS, Feldman KS, Tepe JJ (2012) Palau'amine and related oroidin alkaloids dibromophakellin and dibromophakellstatin inhibit the human $20 \mathrm{~S}$ proteasome. J Nat Prod 75:980-985

39. Nicolaou KC, Krasovskiy A, Majumder U, Trepanier VE, Chen DYK (2009) New synthetic technologies for the construction of heterocycles and tryptamines. J Am Chem Soc 131:3690-3699

40. Shaw E (1955) The synthesis of tryptamines related to serotonin. J Am Chem Soc 77:4319-4324

41. Sengen MO (1996) $\pi$-pyrrole-metal complexes-the missing coordination mode for metal-porphyrin interactions. Angew Chem Int Ed Engl 35:1923-1925

42. Hart JS, Nichol GS, Love JB (2012) Directed secondary interactions in transition metal complexes of tripodal pyrrole imine and amide ligands. Dalton Trans 41:5785-5788

43. Nakanishi $T$ (2011) Supramolecular soft matter: applications in materials and organic electronics. Wiley, Hoboken

44. Muller-Dethlefs K, Hobza P (2000) Noncovalent interactions: a challenge for experiment and theory. Chem Rev 100:143-168

45. Sedlak R, Riley KE, Rezac J, Pitonak M, Hobza P (2013) MP2.5 and MP2.X: approaching $\operatorname{CCSD}(\mathrm{T})$ quality description of noncovalent interaction at the cost of a single CCSD iteration. Chem Phys Chem 14:698-707

46. Friesner RA (2005) Ab initio quantum chemistry: methodology and applications. Proc Natl Acad Sci USA 102:6648-6653

47. Rezac J, Simova L, Hobza P (2013) CCSD[T] describes noncovalent interactions better than the $\operatorname{CCSD}(\mathrm{T}), \operatorname{CCSD}(\mathrm{TQ})$, and CCSDT methods. J Chem Theory Comput 9:364-369

48. Cho Y, Cho WJ, Youn IS, Lee G, Singh NJ, Kim KS (2014) Density functional theory based study of molecular interactions, recognition, engineering, and quantum transport in $\pi$ molecular systems. Acc Chem Res 47:3321-3330

49. Burns LA, Vazquez-Mayagoitia A, Sumpter BG, Sherrill CD (2011) Density-functional approaches to noncovalent interactions: a comparison of dispersion corrections (DFT-D), exchangehole dipole moment (XDM) theory, and specialized functionals. J Chem Phys 134:84107-84114

50. Møller C, Plesset MS (1934) Note on an approximation treatment for many-electron systems. Phys Rev 46:618-622

51. Grimme S, Ehrlich S, Goerigk L (2011) Effect of the damping function in dispersion corrected density functional theory. J Comput Chem 32:1456-1465

52. Goerigk L, Grimme S (2011) A thorough benchmark of density functional methods for general main group thermochemistry, kinetics, and noncovalent interactions. Phys Chem Chem Phys 13:6670-6688

53. Gaussian 09, Revision D.01, Frisch MJ, Trucks GW, Schlegel HB, Scuseria GE, Robb MA, Cheeseman JR, Scalmani G, Barone V, Mennucci B, Petersson GA, Nakatsuji H, Caricato M, Li X, Hratchian HP, Izmaylov AF, Bloino J, Zheng G, Sonnenberg JL, Hada M, Ehara M, Toyota K, Fukuda R, Hasegawa J, Ishida M, Nakajima T, Honda Y, Kitao O, Nakai H, Vreven T, Montgomery JA Jr, Peralta JE, Ogliaro F, Bearpark M, Heyd JJ, Brothers E, Kudin KN, Staroverov VN, Kobayashi R, Normand J, Raghavachari K, Rendell A, Burant JC, Iyengar SS, Tomasi J, Cossi M, Rega N, Millam JM, Klene M, Knox JE, Cross JB, Bakken V, Adamo C, Jaramillo J, Gomperts R, Stratmann RE, Yazyev O, Austin AJ, Cammi R, Pomelli C, Ochterski JW, Martin RL, Morokuma K, Zakrzewski VG, Voth GA, Salvador P,
Dannenberg JJ, Dapprich S, Daniels AD, Farkas Ö, Foresman JB, Ortiz JV, Cioslowski J, Fox DJ (2009) Gaussian, Inc., Wallingford $\mathrm{CT}$

54. Boys DF, Bernardi F (1970) The calculation of small molecular interactions by the differences of separate total energies. Some procedures with reduced errors. Mol Phys 19:553-566

55. Dunning TH Jr (1989) Gaussian basis sets for use in correlated molecular calculations. I. The atoms boron through neon and hydrogen. J Chem Phys 90:1007-1023

56. Halkier A, Helgaker T, Jørgensen P, Klopper W, Koch H, Olsen J, Wilson AK (1998) Basis-set convergence in correlated calculations on $\mathrm{Ne}, \mathrm{N}_{2}$, and $\mathrm{H}_{2} \mathrm{O}$. Chem Phys Lett 286:243-252

57. Platts JA, Grant Hill J, Riley KE, Rezac J, Hobza P (2012) Basis set dependence of interaction energies computed using composite post-MP2 methods. J Chem Theory Comput 9:330-337

58. Zhao Y, Truhlar DG (2007) Density functionals for noncovalent interaction energies of biological importance. J Chem Theory Comput 3:289-300

59. Zhao Y, Truhlar DG (2008) Density functionals with broad applicability in chemistry. Acc Chem Res 41:157-167

60. Chai JD, Head-Gordon M (2008) Long-range corrected hybrid density functionals with damped atom-atom dispersion corrections. Phys Chem Chem Phys 10:6615-6620

61. Goerigk L, Kruse H, Grimme S (2011) Benchmarking density functional methods against the S66 and S66x8 datasets for noncovalent interactions. Chem Phys Chem 12:3421-3433

62. Origin (OriginLab, Northampton, MA)

63. Foster JP, Weinhold F (1980) Natural hybrid orbitals. J Am Chem Soc 102:7211-7218

64. Reed AE, Weinstock RB, Weinhold F (1985) Natural population analysis. J Chem Phys 83:735-746

65. Reed AE, Weinhold F (1985) Natural localized molecular orbitals. J Chem Phys 83:1736-1740

66. Hu H, Lu Z, Yang W (2007) Fitting molecular electrostatic potentials from quantum mechanical calculations. J Chem Theory Comput 3:1004-1013

67. Breneman CM, Wiberg KB (1990) Determining atom-centered monopoles from molecular electrostatic potentials. The need for high sampling density in formamide conformational analysis. J Comput Chem 11:361-373

68. Jurecka P, Sponer J, Cerny J, Hobza P (2006) Benchmark database of accurate (MP2 and $\operatorname{CCSD}(\mathrm{T})$ complete basis set limit) interaction energies of small model complexes, DNA base pairs, and amino acid pairs. Phys Chem Chem Phys 8:1985-1993

69. Rezac J, Riley KE, Hobza P (2011) S66: a well-balanced database of benchmark interaction energies relevant to biomolecular structures. J Chem Theory Comput 7:2427-2438

70. Su P, Li H (2009) Energy decomposition analysis of covalent bonds and intermolecular interactions. J Chem Phys 131:14102-14116

71. Kitaura K, Morokuma K (1976) A new energy decomposition scheme for molecular interactions within the Hartree-Fock approximation. Int J Quantum Chem 10:325-340

72. Ziegler T, Rauk A (1979) Carbon monoxide, carbon monosulfide, molecular nitrogen, phosphorus trifluoride, and methyl isocyanide as.sigma. donors and.pi. acceptors. A theoretical study by the Hartree-Fock-Slater transition-state method. Inorg Chem 18:1755-1759

73. Hayes IC, Stone AJ (1984) An intermolecular perturbation theory for the region of moderate overlap. Mol Phys 53:83-105

74. Schmidt MW, Baldridge KK, Boatz JA, Elbert ST, Gordon MS, Jensen JH, Koseki S, Matsunaga N, Nguyen KA, Su S, Windus TL, Dupuis M, Montgomery JA (1993) General atomic and molecular electronic structure system. J Comput Chem 14:1347-1363 
75. Gordon MS, Schmidt MW (2005) Theory and applications of computational chemistry: the first forty years. In: Dykstra CE, Frenking G, Kim KS, Scuseria GE (eds) Advances in electronic structure theory: GAMESS a decade later. Elsevier, Amsterdam

76. Carrazana-Garcia JA, Cabaleiro-Lago EM, Campo-Cacharron A, Rodriguez-Otero J (2014) A theoretical study of ternary indolecation-anion complexes. Org Biomol Chem 12:9145-9156

77. Campo-Cacharron A, Cabaleiro-Lago EM, Carrazana-Garcia JA, Rodriguez-Otero J (2014) Interaction of aromatic units of amino acids with guanidinium cation: the interplay of $\pi \cdots \pi, \mathrm{X}-\mathrm{H} \cdots \pi$,

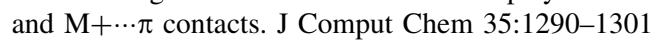

78. Priya AM, Senthilkumar L, Kolandaivel P (2014) Hydrogenbonded complexes of serotonin with methanol and ethanol: a DFT study. Struct Chem 25:139-157

79. Pereira Orenha R, Vessecchi R, Galembeck SE (2015) The resonance of cation and anion radicals with multiple conjugated bonds. Struct Chem 26:365-373
80. Jimenez-Moreno E, Jimenez-Oses G, Gomez AM, Santana AG, Corzana F, Bastida A, Jimenez-Barbero J, Luis Asensio J (2015) A thorough experimental study of $\mathrm{CH} / \pi$ interactions in water: quantitative structure-stability relationships for carbohydrate/ aromatic complexes. Chem Sci. 6:6076-6085

81. Kruszynski R, Sierański T (2015) Can stacking interactions exist beyond the commonly accepted limits? Cryst Growth Des. doi:10.1021/acs.cgd.5b00852

82. Ninkovic DB, Andric JM, Zaric SD (2013) Parallel interactions at large horizontal displacement in pyridine-pyridine and benzenepyridine dimers. Chem Phys Chem 14:237-243

83. Ninkovic DB, Janjic GV, Veljković DZ, Sredojevic DN, Zaric SD (2011) What are the preferred horizontal displacements in parallel aromatic-aromatic interactions? Significant interactions at large displacements. Chem Phys Chem 12:3511-3514 